\title{
Knowledge and skills attractive for the employers of the organic sector: A survey across Europe
}

\section{Briz, Teresa}

2020-12

Briz , T, von Fragstein und Niemsdorff , P , Radicetti , E , Moscetti , R , Uusitalo , E , livonen , S , Mynttinen , R, Moudry , J , Konvalina , P , Kopecky , M , Srednicka-Tober , D , Kazimierczak , R , Talgre , L, Matt , D , Veromann , E, Mancinelli , R \& Rembialkowska , E 2020 , ' Knowledge and skills attractive for the employers of the organic sector: A survey across Europe ' , Renewable Agriculture and Food Systems (Print), vol. 35 , no. 6 , pp. 710-719 . https://doi.org/10.1017/S1742170519000395

http://hdl.handle.net/10138/324607

https://doi.org/10.1017/S1742170519000395

cc_by_nc_nd

acceptedVersion

Downloaded from Helda, University of Helsinki institutional repository.

This is an electronic reprint of the original article.

This reprint may differ from the original in pagination and typographic detail.

Please cite the original version. 
Rembiałkowska E., von Fragstein und Niemsdorff P., Briz T., Mancinelli R., Radicetti E., Moscetti R., Uusitalo E., Iivonen S., Mynttinen R., Moudry J., Moudry J. , Konvalina P., Kopecky M., Średnicka-Tober D., Kazimierczak R., Luik A., Matt D., Veromann E.

Knowledge and skills attractive for the employers of the organic sector: A survey across Europe

\begin{abstract}
In all countries, the organic sector of the agricultural industry is increasing, with Europe traditionally leading this trend. A survey of different stakeholders (employers) was carried out in 2015 in seven European countries to evaluate the employment market for the organic agricultural industry in Europe. Results indicate the willingness to employ qualified graduates. From the employers' perspective, the most desirable knowledge skills among the graduates of organic agricultural studies include plant production, food quality, and plant protection. Further, the study revealed the work skills most desired by the employers are practical expertise, teamwork, and problem-solving, and the most important method of learning is cooperation with enterprises (internships/training) in the organic agricultural sector.
\end{abstract}

Keywords organic, stakeholders, education, employment, skills. 


\section{Introduction}

It is well known that organic agricultural production is developing dynamically around the world as the number of farmers converting to organic production increases (Willer and Lernaud, 2016; Eurostat 2018). As has been shown in studies, agricultural research and education in Europe has played a major role in the advancement of agriculture and land use (Porceddu and Rabbinge, 1997; Mulder and Kupper, 2006). Productivity per hectare - the efficiency and efficacy of external inputs - has increased as the scientific basis of agriculture has expanded through the adoption of new knowledge and technology (Kivinen et al., 2000; Chaplin et al., 2004; Akkademahadevi et al., 2018). Nevertheless, the future of agricultural education depends on more than just higher yields; it also needs a broader view that includes environmental conservation and protection, climate change mitigation tools, sustainable agriculture, precision agriculture and technology, geoinformation systems, and innovative agricultural entrepreneurship (Porceddu and Rabbinge, 1997; Mulder and Kupper, 2006). Societies are changing, and so should agricultural education. Graduate and undergraduate studies in agriculture and agricultural engineering, along with agricultural vocational training schools, are examples of the broad changes in education in agriculture and natural resources (Kunkel et al., 1996). This is a key issue because some researchers believe agriculture is not undergoing a generational change, which is not the case of organic farms, where organic farmers are often younger than their non-organic counterparts (Green and Maynard, 2006). In consequence, the younger generation needs to be better prepared for the changes in agriculture and its markets, which are driven by higher incomes and greater demand of high-income elasticity goods and services. Issues such as health concerns, environmental respect, and food quality are motivating the organic revolution, which is well-known, yet not widely implemented in the agricultural studies. 
Few research studies have acknowledged the importance of education in agriculture, especially the importance of the future employability of students in the organic sector of the agricultural industry. Organic farming requires more labor than conventional farming, and leads to higher rural employment (Jansen, 2000; Offermann and Nieber, 2000), which should be an incentive for agricultural education programs. We present an innovative study to provide the point of view of stakeholders toward employing qualified graduates in their companies. To our knowledge, this study is the first time organic agriculture industry stakeholders (employers) across Europe have answered questions related to issues about the appropriateness of current agricultural education and training for employment in the organic agriculture industry, stakeholders' interest in training students for employment, and what kind of abilities and skills are needed for employment.

\section{Empirical methods}

\section{Survey procedures}

A survey with stakeholders from all links of the organic food chain was carried out in 2015 in seven European countries: Czech Republic, Estonia, Finland, Germany, Italy, Poland, and Spain. The study was designed and conducted by partner universities of the European project titled "Innovative Education toward the Needs of the Organic Sector" (https://epos-project.net/). The University partners were (1) Warsaw University of Life Sciences, (2) Universidad Politécnica de Madrid, (3) University of Kassel, (4) University of Helsinki, (5) Estonian University of Life Sciences, (6) University of South Bohemia in Ceske Budejovice, and (7) Università degli Studi della Tuscia.

The main objective of the survey was to identify the knowledge and skills most attractive to stakeholders (employers) in the organic agriculture sector for the agricultural education sector. Stakeholders included ministries and other public bodies, certification 
bodies, advisory services, education and expert organizations, farmers, processors, and traders. All stakeholders interviewed followed or were familiar with Organic European Regulation n. 834/2007 concerning organic production and labelling (and repealing Regulation n. 2092/91). Stakeholders were contacted through national organic agriculture networks to obtain the largest possible sample (Casagrande et al., 2016), and then randomly selected based on their availability to participate in the survey.

A questionnaire with closed-ended and open-ended questions was created by the project partners to encompass the diversity among the stakeholders (Table 1). To test whether the questions were understandable, several non-target groups were asked to read and answer the survey. Closed-ended questions were drawn up in order to cover the diversity among the stakeholders. This allowed a statistical approach to multi-component analysis to reveal groups of stakeholders with similar behaviors or attitudes. Open-ended questions were added to obtain additional information for certain answers.

\section{[Insert Table 1]}

\section{Table 1. Number of responses from stakeholders* (SH) in each country (CO)}

The questionnaire was divided into five sections. The first section included the socioeconomic demographics of the stakeholders and information about their business or institution. The second section included questions related to the willingness to employ graduates in the organic agricultural industry. Stakeholders indicating a positive answer were subsequently asked to indicate their preference on the educational level of their employees (high school graduate, vocational school, bachelor, master degree, etc.). In addition, respondents were asked to rank in a five-point Likert scale the theoretical knowledge and practical skills they would expect from graduates. Beyond this information, respondents were asked about their level of satisfaction with the current 
degree of skills of university graduates in organic agriculture, and their preferences between traditional and more innovative teaching methods.

The questions were first written in English to establish a common understanding among the partners, and then translated into the national languages of the partners' countries. National languages were used to make it easier for the respondents to understand and answer the questions. This also strengthened the validity of the research and increased the willingness to participate in the survey. Next, the answers to the openended questions were translated from the national languages to English. In both cases, attention was paid to careful translations so as not to lose any information in the dual translation process.

Acceptable response rates were achieved by using two data collection techniques: structured interview and on-line survey. Interviews with individual stakeholders were conducted by researchers who were instructed to read questions exactly to avoid influencing the respondents in any way, and complete the questionnaire according to each respondent's replies. The on-line survey was delivered via websites and social media (Facebook). It was also possible to combine these two data collection techniques. The partners were free to choose the technique that best suited them.

\section{Description of interviewed stakeholders}

Detailed information regarding the number and socioeconomic demographics of the stakeholders for each country is reported in Tables 1 and 2, respectively. Our data come from a unique dataset of 700 interviews with 537 stakeholders. In some cases, a person represented two different categories (e.g., processor and salesman), so sometimes two responses were collected from the same person. This explains why the number of respondents $(\mathrm{CO})$ was lower than number of responses $(\mathrm{SH})$ in Table 1. Like Casagrande et al. (2016), the objective was to collect at least 30 surveys per country. 
The most represented groups in the survey (as well as in the real-world scenario) were farmers and processors, while the least represented groups were importers/exporters, certifiers, and representatives of the public services (Table 1). Data in Table 2 indicate that most of the respondents in all the countries were in the 41-60 age category, and the smallest group in the 60 and over age category. There were big differences in the years worked in the organic agricultural sector among the individual countries (this corresponds to years of membership in the European Union [EU]), but altogether, most of the stakeholders were active for 3-13 years. One important consequence was earlier access to EU subsidies for the older EU-member states.

\section{[Insert Table 2]}

\section{Table 2. Respondents' ages and years in organic sector for each country}

The survey focused on the most interesting findings presented in five groups of thematic points: (1) degree of graduate for optional employment, (2) profile of disciplines of graduates, (3) strategies for recruitment of graduates, (4) skills requirement, and (5) teaching innovations.

\section{Statistical analysis}

All data in the dataset were distributed within a scoring system, ranking from 1 to 5 ('undesirable / disagree' by scores 1 and 2; 'no opinion' by score 3; 'desirable / agree' by scores 4 and 5). Nonparametric Kruskal-Wallis ANOVAs were applied using the Minitab17(C) statistical software. Means were compared with the Dunn-Bonferroni multiple comparisons test. Evaluations were carried out by clustering whole questions of the dataset: (a) per thematic point, (b) per partner country, and (c) per stakeholder. Stakeholders were categorized as (1) farmers, (2) processors, (3) salesmen, (4) 
import/export representatives, (5) consultants, (6) certifiers, (7) public service representatives, and (8) educators.

It is important to underline that all figures (1-5) are prepared for the whole dataset of stakeholders' answers (700) in all countries. Tables 3-7 present detailed information (see Results section).

It is also important to say that the statistical tools used allowed us to overcome the problem of the uneven number of responses from different stakeholder groups. The $\mathrm{N}$ per variant or minimum/maximum per variant group is included in the tables and figures. There are no weaknesses due to under-sized groups.

\section{Results}

\section{Type of graduate}

We were interested in studying the 'type of graduate' preferred by the different stakeholders of the organic sector for optimal employment. The possible answers to this question were six fixed replies: three for academic degrees and three for non-academic degrees. The ranking of estimates of the six replies over all country data is presented in Figure 1. Our results showed that stakeholders generally preferred to hire employees with vocational school and bachelor degrees rather than $\mathrm{PhD}$ degrees (Figure 1). Generally, the least preferred employees were the ones with $\mathrm{PhD}$ degrees, as there were statistically significant differences between the $\mathrm{PhD}$ degree and all other degrees.

\section{[Insert Figure 1]}

\section{Figure 1. Preferred degrees of graduates for employment (all stakeholders together)}

The preferred degrees for stakeholders employing graduates in the organic sector are presented in Table 3 . The $\mathrm{PhD}$ degree was the most desirable by educators and public sector representatives, and the least desirable by salesmen, farmers, and processors. The 
vocational school degree was the most desirable by farmers, processors, and salesmen, and least desirable by certifiers and educators.

\section{[Insert Table 3]}

Table 3. Desirability of selected educational degrees of graduates for different stakeholders

\section{Profile of discipline of graduates}

In line with the type of graduate preferred, we delved into the subject of the theoretical knowledge expected from graduates. Results of the survey for all stakeholders from all countries clearly showed a preference for the disciplines of plant production, plant protection, and animal production on the production side; food quality and food technology on the food system side; and marketing and legislation on the economics and juridical sides (Figure 2). The least desirable graduate discipline-profiles were arithmetic, biotechnology, and finances. Again, due to the distinctly different needs of the various stakeholders, there were clear differences within the answers for the same topics (Table 4).

\section{[Insert Figure 2]}

Figure 2. Desirable discipline-profiles of graduates for employment (all stakeholders together)

\section{[Insert Table 4]}

Table 4. Desirability of selected knowledge areas of graduates for different stakeholders 
Knowledge in plant production receives a high score from farmers, certifiers, and educators (level of agreement, 82-90\% desirable), results which significantly differ from those of processors and salesmen (level of agreement, 50-57\% desirable and $29 \%$ undesirable). Food technology receives a high score from processors, importers/exporters, and salesmen (level of agreement, $82 \%$ and $73 \%$, respectively). By contrast, only $52-54 \%$ of consultants and farmers desire the same background; differences between these two groups of stakeholders are significant (Table 4). Also, there are significant distinctions between the replies of the stakeholders from various countries (Table 5). For example, plant production is significantly more desired by stakeholders from Estonia and Spain ( $81 \%$ and $86 \%$, respectively) than by stakeholders from Germany and Poland (65\% and 58\%, respectively).

\section{[Insert Table 5]}

Table 5. Desirability of selected knowledge areas of graduates in different countries (for all stakeholders together)

\section{Strategies for recruitment}

The question of how new employees are recruited was posed to the different stakeholders, with six possible answers provided: recommendations, people known by recruiter, internships (training), other methods, advertisements on Internet, and advertisements in print media (Figure 3). The results show that the stakeholders prefer to follow an informal recruitment channel (recommendations, people known by recruiter), rather than formal channels (advertisements on Internet or in print media). The difference between informal and formal recruitment channels is significant.

\section{[Insert Figure 3]}


Figure 3. Strategies of recruitment for employment of graduates (all stakeholders together)

\section{Skills requirements}

Desirability of different skill requirements by graduates for the stakeholders is presented in Figure 4. Analysing all the skills together shows that the most desirable skills are practical expertise, teamwork, and analytical/problem solving.

\section{[Insert Figure 4]}

Figure 4. Desirability of different skills of graduates by potential employers (all stakeholders together)

Table 6 also presents details regarding the desirability of different skills by stakeholders. Generally, all skills together are most desired by consultants (75\%). This result is understandable because consultants need higher knowledge and skills in their profession.

\section{[Insert Table 6]}

Table 6. Desirability of knowledge areas/skills of graduates for stakeholders (treated separately and whole group)

Table 6 also illustrates the desirability of the graduates' knowledge and skills for in particular countries. Finnish and Estonian stakeholders were the most interested in the knowledge and skills of the graduates, while Italian, German and Polish stakeholders were the least interested. The difference was statistically significant. 


\section{Teaching methods}

The last part of the survey is illustrated in Figure 5. In the opinion of all stakeholders together, the most desired innovation in academic teaching is learning by cooperation with enterprises (>81\%), followed by learning by defining and solving problems $(>75 \%)$ and learning by teamwork on specific projects $(>60 \%)$.

\section{[Insert Figure 5]}

Figure 5. Approach to innovation in teaching (all stakeholders together)

Table 7 shows detailed information regarding the approach to innovations in teaching graduates. Consultants and certifiers are the most interested in teaching innovations (84\% and 86\%, respectively), while farmers and processors are the least interested (71\% and $72 \%$, respectively). Again, this is in line with the previous results because consultants and certifiers are directly interested in the modern skills of graduates.

\section{[Insert Table 7]}

Table 7. Approach to innovations in teaching (1) common ranking by different stakeholders, (2) common ranking by individual countries

Examining the country-specific data, Italian and Czech stakeholders are slightly more interested in the teaching innovations than their colleagues from other countries, but the differences are not significant. The least interested in teaching innovations are surprisingly the German stakeholders. In general, all stakeholders indicated a high preference (agreement-level $>70 \%$ ) toward new teaching approaches (i.e., problemsolving, teamwork, and practice-based strategies). 


\section{Discussion}

The literature research indicates that the topic of employers' (stakeholders) demand for better qualified graduates within the organic sector is new, and the present study is one of the first to analyse this issue.

The present study shows that the most attractive degree for stakeholders is vocational education, followed by $\mathrm{BSc}, \mathrm{MSc}$, and $\mathrm{PhD}$ studies. The result that employees with $\mathrm{PhD}$ degrees are not preferred by stakeholders is not surprising in the context of the practical professions offered by the organic agriculture industry. We have to consider the positions of the stakeholders (Table 1), which clearly differentiate between those more focused on personnel with practical skills (farmers, processors, and salesmen) and those more focused on personnel with theoretical knowledge (educators and public service).

The type of education degree can have a strong influence on how graduates perceive agriculture (as one total component or groups of individual components). Both the general and specific approaches can be very productive in scientific terms. The first by the implementation and derivation of practical rules, and the second by gaining understanding in some of the basic processes involved. The distinction between the two approaches has its counterpart in education and training (Porceddu and Rabinge, 1997).

Different studies report higher values for labor in the organic sector than in the conventional sector (Offermann and Nieber, 2000), in addition to greater demand for employees, thus helping to reverse the decline in the agricultural labor force, which has fallen in the last decades (Green and Maynard, 2006). Agricultural employment has decreased by $2 \%$ per year during the last 25 years, although the number of EU agricultural employment still exceeds 5\% (Porceddu and Rabinge, 1997). The effect of education on agriculture professionals shows that studies incorporating organic agriculture has a positive influence for adopting environmentally friendly practices (Padel, 2001; Wheeler, 
2008; Kallas et al., 2010), and that better educated, as well as younger, professionals are more likely to adopt the organic farming certification (Aubert and Enjolras, 2017). Data suggest that formal education has a positive influence on students' perception of the benefits of organic agriculture (Nunez et al., 2014), with organic agriculture classes increasingly being offered (Hilimire and McLaughlin, 2015). More students are interested in alterative food systems, with a strong accent on organic methods. Students are also interested in related subjects, such as health, environmental sustainability, accessibility, and social justice. Even so, Williams and Wise (1997) discovered that despite high school students being positive about the potential impel of sustainable agriculture, they do not fully understand how sustainable agriculture components fit together and relate to social goals such as quality water, safe food, and preservation of natural resources. There needs to be better development of teaching and learning initiatives for sustainable (organic) agriculture in schools for students majoring in agriculture.

Taking into account the fact that the organic market growth is increasing, stakeholders are interested in topics clearly connected to practical needs such as plant production, plant protection, and animal production, as well as topics related to food quality and marketing. Stakeholders are aware of the importance of the future of green marketing and its potential effect on the agricultural industry (Byrla, 2015).

Regarding strategies for recruitment, we found that organic agriculture stakeholders significantly prefer informal routes. There has always been a distinction between the formal (advertisements, job agencies, etc.) and informal (word-of-mouth methods, social connections, etc.) recruitment methods. Informal recruitment methods are often used for screening new personnel in many types of jobs (Flap and Boxman, 2001; Marsden and Gorman, 2001; Breaugh, 2013) because they provide more accurate information about prospective employees (Gërhxani and Koster, 2015). Using informal 
recruitment methods has additional advantages besides the obvious speed and cost of the process (Watson, 1989; Carroll et al., 1999).

One of the major issues of recruitment is knowing what makes graduates employable. Results from our study show that for stakeholders (employers), the most attractive skills are the practical expertise, teamwork, and problem solving skills, while the least attractive skills are working in a lab, knowledge in specific computer software, and expertise in financial issues. Previous studies have shown that small firms have problems in attracting the staff they need, often due to low salaries (Atkinson and Storey, 1994), and lack of basic skills, especially among younger workers (Carroll, 1999). Kunkel et al. (1996) posit that "the most important step in implementing the needed fundamental changes in higher education in agriculture and natural resources is to gain a perceptive understanding of the society and the industries for which our graduates must be readied." That is why this issue is so relevant and there is the clear need to know the demands of stakeholders (employers). Karsten and Risius (2004) report that stakeholders complain about graduates being deficient in skills such as writing, speaking, problem solving, data collection, and learning on their own. Moreover, stakeholders report that graduates have low awareness of environmental issues, and different cultures and attitudes. According to our study, highly desired skills are analytical/problem solving expertise and ability to adapt/act in new situations. A study by Gil et al. (2015) confirms these findings, adding that additional training is needed to improve employees' competencies (i.e., the ability to act in new situations is an important basic skill).

Humburg et al. (2013) states that professional expertise is the most important skill set that affects graduates' employability. Other important skills are interpersonal skills, relevant work experience, innovative/creative skills, and commercial/entrepreneurial skills. There is high interest in the practical skills and internship experience. 
Regarding teaching methods, our results clearly indicate that innovations in the teaching/learning process are necessary within organic agricultural education. The order of preference by stakeholders is learning by cooperation with enterprises/other representatives of the organic sector, learning by defining and solving problems, and learning by teamwork on specific projects (Figure 5).

The conclusions reached in the study by Butun et al. (2008) are relevant for the present study. The authors find the problem-based learning (PBL) approach is an effective method to cope with stakeholders' (employers) demands, especially the ability to find and filter proper information, to work both independently and as part of a team, to acquire new knowledge, and to take the initiative. Achieving these professional skills requires good social skills and learning abilities. Hilimire (2016) find that effective approaches include emphasizing interdisciplinary skills while balancing experience, theory, and practical skills acquisition. Penttinen et al. (2013) state that all didactic practices should aim at paralleling the holistic construction of students' careers with their well-being to facilitate students' transition from university to working life. Hilimire et al. (2014) find that neither traditional nor non-traditional agricultural education programs explicitly address food systems from a global, structural, and sociocultural perspective. Hilimire (2016) further finds that students participating in these courses develop deep critical thinking skills around value-based difficult issues to solve complicated food systems problems. The need to combine a study program with internships or training in companies can be the key for successful employment (Karsten and Risius, 2004).

In summary, professional agricultural educators need to think strategically about what needs to be accomplished to prepare the human resources required for feeding the world's population and protecting the environment and, where necessary, be prepared to shed traditions that constrain the profession. Making improvements in the quality of 
higher agricultural education worldwide will depend on a variety of interrelated changes. Some changes will require efforts at the individual institutional level while others will require global cooperation (Acker, 1999).

\section{Conclusions}

We have evaluated at the European scale the needs of the job market of different stakeholders, and can offer some new findings relevant for future educational activities within organic agriculture. There is a clear willingness to employ graduates in organic agriculture, which is crucial for both the education system and the sector; however, there is no common agreement in the level of studies (varying from vocational education to doctorate studies) to best achieve this. From the stakeholders' (employers) point of view, the most desirable knowledge among graduates of organic agricultural studies is plant production, food quality, and plant protection, while the most desired skills are practical expertise, teamwork, and problem solving skills. We can conclude that stakeholders are not satisfied with the level of knowledge of the current graduates, and point out that traditional teaching methods may not be the most adequate ones. Teaching methods should be adapted to the needs of the stakeholders (employers) and innovative tools are necessary. It is important to increase cooperation with companies or other representatives of the organic sector, and to learn by defining and solving problems in order to have a broader understanding of the situation. This can be a challenge for current study programs of all levels across Europe, but we think it is the starting point to ensure a successful organic sector which, year after year, is increasing its presence all over the world.

\section{Acknowledgements}


This study has been funded by the project 'Innovative Education towards the Needs of the Organic Sector' acronym EPOS no. 2014-1-PL1-KA203-003392. The authors are grateful for the possibility of participating in this project and collecting study materials. 


\section{References}

Acker, D.G. 1999. Improving the quality of higher education in agriculture globally in the 21st century: Constraints and opportunities. Journal of International Agricultural and Extension Education 6:47-53

Akkamahadevi, H., Sreenivasulu, M., Sreenivasa, R., and M. Lankati. 2018. A study on knowledge level of farmers on organic red gram cultivation practices in drylands areas of Karnakata, India. International Journal of Current Microbiology and Applied Sciences 7:435-440

Atkinson, J. and Storey, D. 1994. Small firms and employment. In J. Atkinson and D. Storey (eds). Employment, the Small Firm, and the Labour Market. Routledge, London.

Aubert, M. and G. Enjolras. 2017. French labour-force participation in organic farming. Human Systems Management 36:163-172

Breaugh, J.A. 2013. Employee recruitment, Annual Review of Psychology 64:389-416.

Butun, E., Erkin, H.C., and Altintas, L. 2008. A new teamwork-based PBL problem design for electrical and electronic engineering education: A systems approach. International Journal of Electrical Engineering Education 45:110-120.

Byrla, P. 2015. The development of organic food market as an element of sustainable development concept implementation. Problems of Sustainable Development $10: 79-88$

Carroll, M., Marchington, M., Earnshaw, J., and S. Taylor. 1999. Recruitment in small firms: Processes, methods and problems. Employee Relations 21:236-250.

Casagrande, M., Peigné, J., Payet, V., Mäder, P., Sans, F.X., Blanco-Moreno, J.M., Antichi; D., Bàrberi; P., Beeckman A., Bigongiali, F., Cooper, J., Dierauer, H., Gascoyne, K., Grosse, M., Heß, J., Kranzler, A., Luik, A., Peetsmann, E., 
Surböck, A., Willekens, K., and David, C. 2016. Organic farmers' motivations and challenges for adopting conservation agriculture in Europe. Organic Agriculture 6:281-295.

Chaplin, H., Davidova, S., and M. Gorton. 2004. Agricultural adjustment and the diversification of farm households and corporate farms in Central Europe. Journal of Rural Studies 20:61-77.

Eurostat. 2018. Organic operators by status of the registration process (from 2012 onwards). EU Open Data Portal, Eurostat.

Flap, H.D. and E.A.W. Boxman. 2001. Getting started: The influence of social capital on the start of the occupational career. In N. Lin, K. Cook, and R. Burt (eds). Social Capital: Theory and Research. Aldine de Gruyter, New York, pp. 159-185

Gërxhani, K. and F. Koster. 2015. Making the right move. Investigating employers' recruitment strategies. Personnel Review 44:781-800

Gil, A.J., Garcia-Alcaraz, J.L., and M. Mataveli. 2015. The training demand in organizational changes processes in the Spanish wine sector. European Journal of Training and Development 39:315-331.

Green, M. and R. Maynard. 2006. The employment benefits of organic farming. What will organic farming deliver? Aspects of Applied Biology 79:51-55.

Hilimire, K. 2016. Theory and practice of an interdisciplinary food systems curriculum. North American Colleges and Teachers of Agriculture Journal 60:227-233.

Hilimire, K., Gillon, S., McLaughlin, B.C., Dowd-Uribe, B. and Monsen, K.L. 2014. Food for thought: Developing curricula for sustainable food systems education programs. Agroecology and Sustainable Food Systems 38:722-743. 
Hilimire, K. and McLaughlin, B.C. 2015. Students' suggestions for food systems curricula at a liberal arts college. Agroecology and Sustainable Food Systems 39:845-860.

Humburg, M., van der Velden, R., and A. Verhagen. 2013. The employability of higher education graduates: the employers' perspective. Final Report. Publications Office of the European Union, Luxembourg.

Jansen, K. 2000. Labour: Livelihoods and the quality of life in organic agriculture in Europe. Band 17:247-278

Kallas, Z., Serra, T., and Gil, J.M. 2010. Farmers' objectives as determinants of organic farming adoption: The case of Catalonian Vineyard production. Agricultural Economics 41:247-278

Karsten, H.D. and Risius, M.L. 2004. Development of an interdisciplinary agroecology major with input from surveys of students, graduates, and employers. North American Colleges and Teachers of Agriculture Journal 48:58-64.

Kivinen, O., Nurmi, J., and Salminiitty, R. 2000. Higher education and graduate employment in Finland. European Journal of Education 35:165-177.

Kunkel, H.O., Skaggs, C.L., and Maw, I.L. 1996. Revolutionizing Higher Education in Agriculture: Framework for Change. Iowa State University Press, Ames, IA.

Marsden, P.V. and Gorman, E.H. 2001. Social networks, job changes, and recruitment. In I. Berg, and A. Kalleberg (eds). Sourcebook of Labor Markets: Evolving Structures and Processes. Kluwer/Plenum Publishers, New York, pp. 467-502

Mulder, M. and Kupper, H. 2006. The future of agricultural education: The case of the Netherlands. Journal of Agricultural Education and Extension 12:127-139

Nunez, G.H., Kovaleski, A.P., and Darnell, R.L. 2014. Formal education can affect students' perception of organic produce. HortTechnology 24:64-70. 
Offermann, F. and Nieber, H. 2000. Economic performance of Organic Farms in Europe. Organic Farming in Europe: Economics and Policy, volume 5. Hohenheim University, Stuttgart, Germany.

Padel, S. 2001. Conversion to organic farming: A typical example of the diffusion of an innovation? Sociologica Ruralis 41:42-61

Penttinen, L., Skaniakos, T., and Lairio, M. 2013. Supporting students' pedagogical working life horizon in higher education. Teaching in Higher Education 18:883894.

Porceddu, E. and Rabinge, R. 1997. Role of research and education in the development of agriculture in Europe. Developments in Crop Science 25:3-15.

Watson T. 1989. Recruitment and selection. In K. Sisson (ed.). Personnel Management in Britain. Blackwell, Oxford, UK.

Wheeler, S.A. 2008. What influences agricultural professionals' views towards organic agriculture? Ecological Economics 65:145-154.

Willer, H. and Lernaud, J. 2016. The World of Organic Agriculture: Statistics and Emerging Trends 2016. Research Institute of Organic Agriculture (FiBL) and IFOAM-Organics International, Frick, Switzerland and Bonn, Germany.

Williams, D.L. and Wise, K.L. 1997. Perceptions of Iowa high school agricultural education teachers and students regarding sustainable agriculture. Journal of Agricultural Education 38:15-20. 
Figure 1. Estimates of questions about preferred degree of graduates for employment

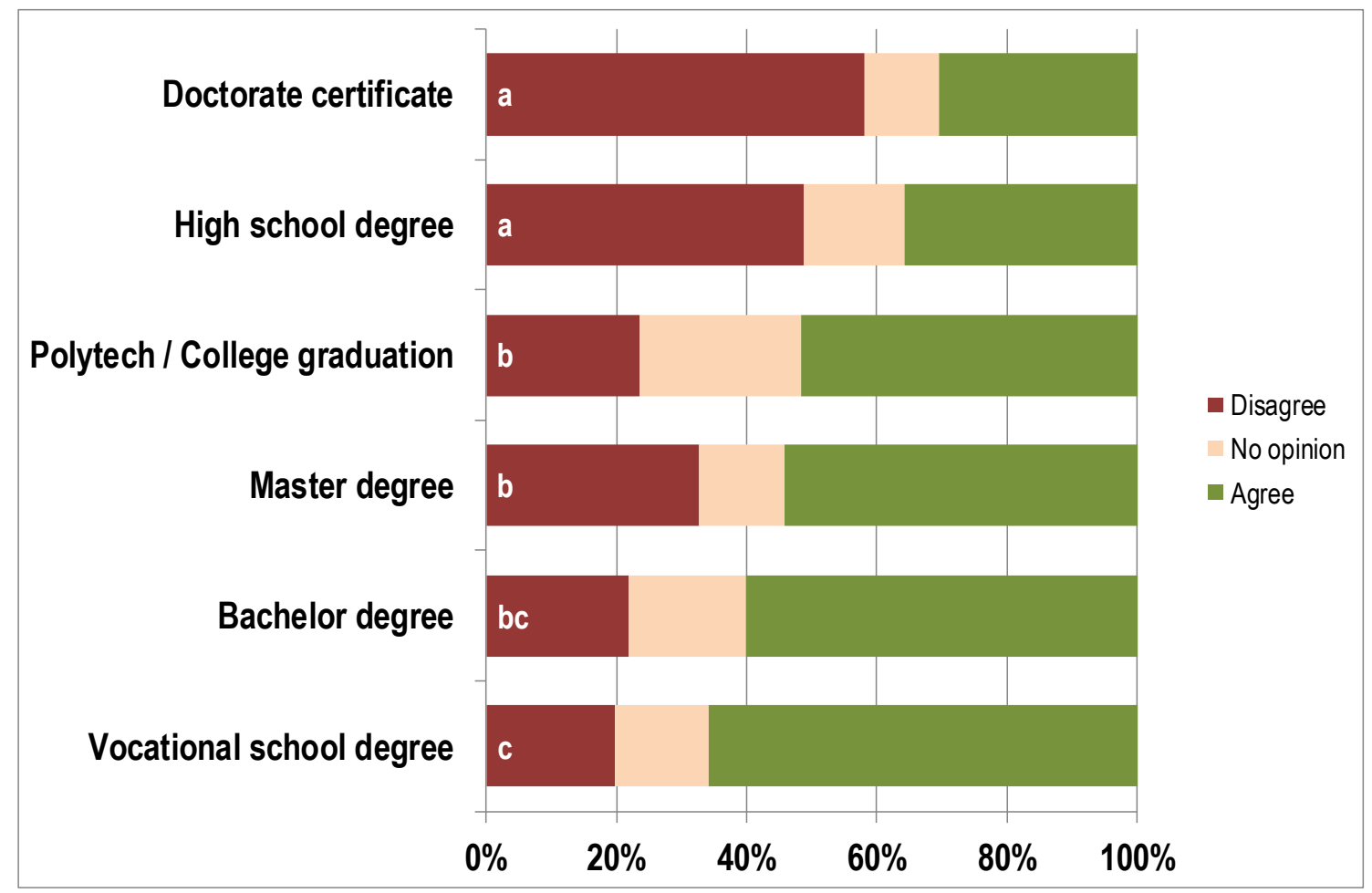

Note: Summary of all interviews per country with a scored system of reply ( 1 to 5 , from worst to best, $1 \& 2=$ disagree, $3=$ no opinion, $4 \& 5=$ agree). Different letters stand for significant differences according to Dunn Bonferroni Test for multiple comparisons of Kruskal-Wallis evaluations. 
Figure 2. Estimates of questions about expected discipline-profile of graduates for employment

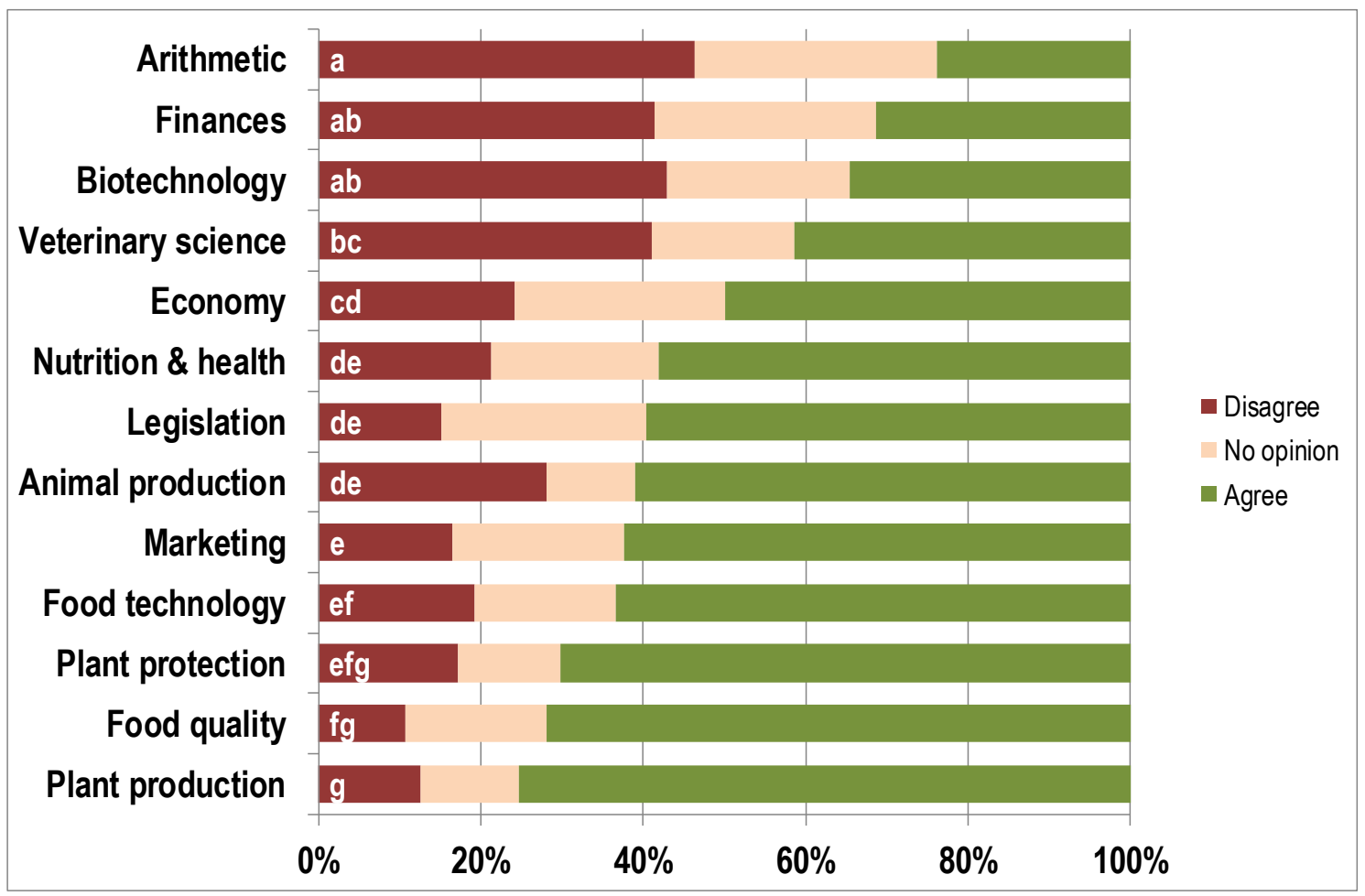

Note: Summary of all interviews per country with a scored system of reply (1 to 5, from worst to best, $1 \& 2=$ disagree, $3=$ no opinion, $4 \& 5=$ agree). Different letters stand for significant differences according to Dunn Bonferroni Test for multiple comparisons of Kruskal-Wallis evaluations. 
Figure 3. Estimates of questions about strategies of recruitment for the employment of graduates

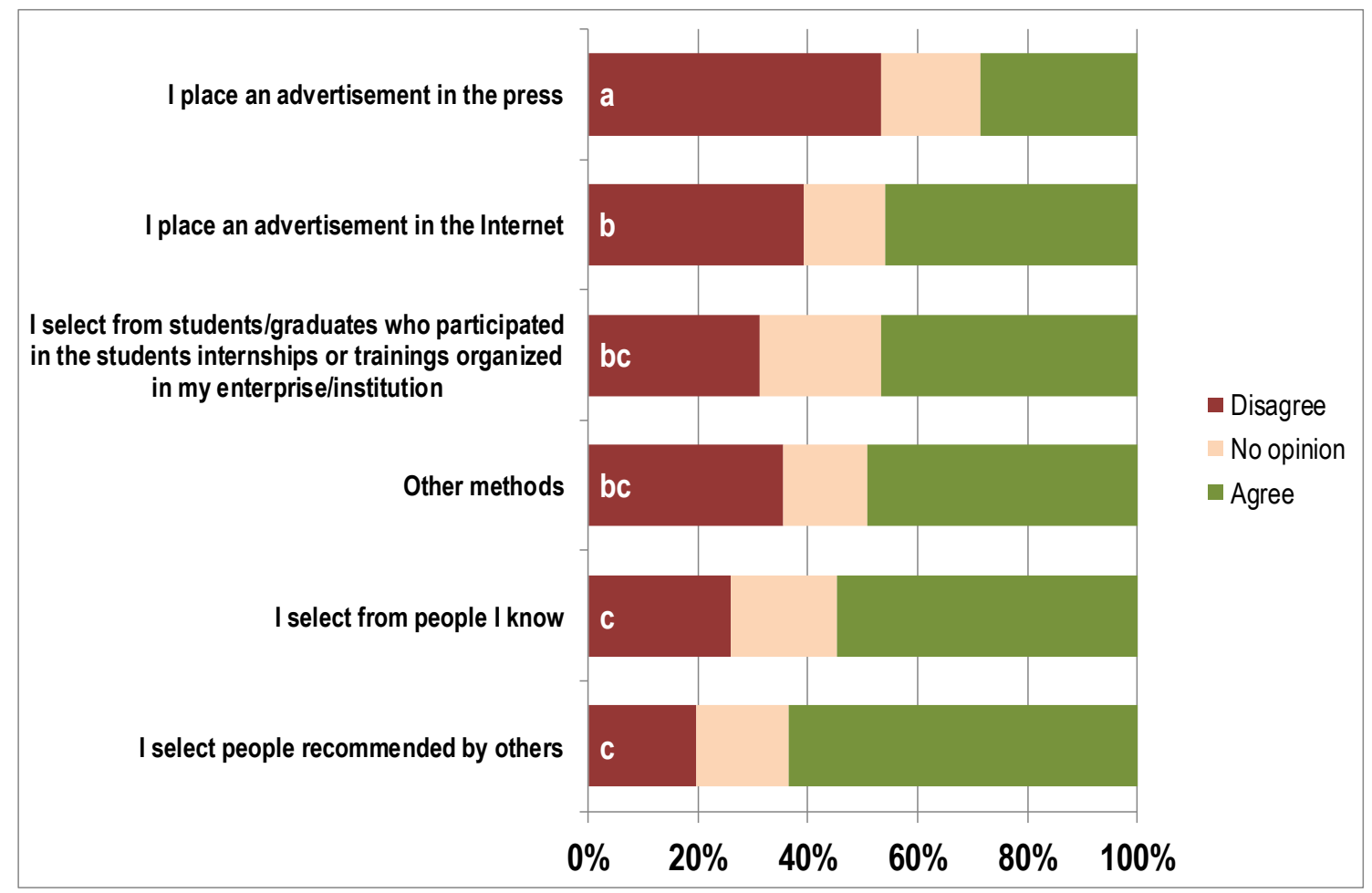

Note: Summary of all interviews per country with a scored system of reply ( 1 to 5, from worst to best, $1 \& 2=$ disagree, $3=$ no opinion, $4 \& 5=$ agree). Different letters stand for significant differences according to Dunn Bonferroni Test for multiple comparisons of Kruskal-Wallis evaluations. 
Figure 4. Estimates of questions about skills requirement for graduates

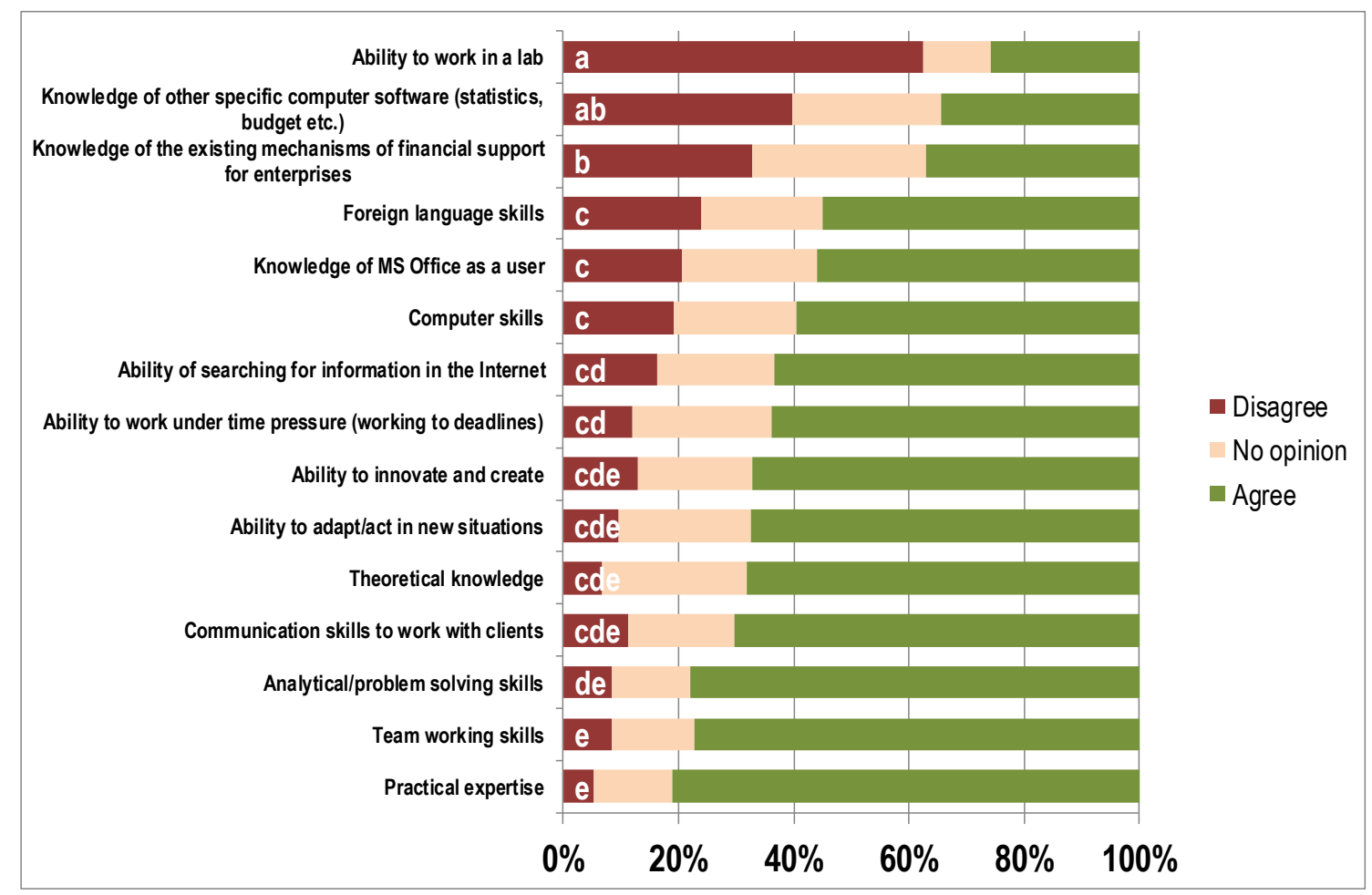

Note: Summary of all interviews per country with a scored system of reply (1 to 5, from worst to best, $1 \& 2=$ disagree, $3=$ no opinion, $4 \& 5=$ agree). Different letters stand for significant differences according to Dunn Bonferroni Test for multiple comparisons of Kruskal-Wallis evaluations. 
Figure 5. Estimates of questions about innovations in teaching

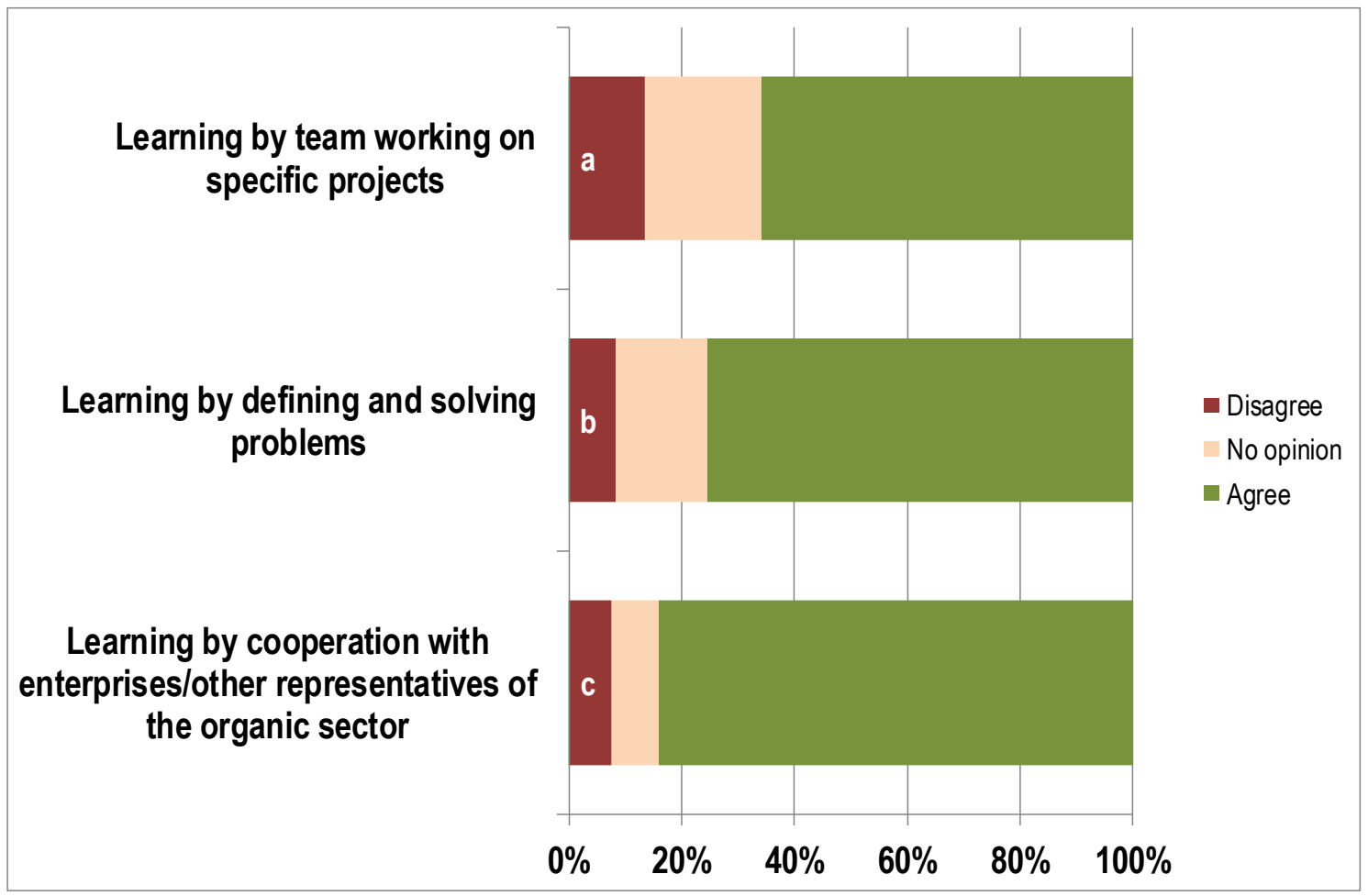

Note: Summary of all interviews per country with a scored system of reply ( 1 to 5 , from worst to best, $1 \& 2=$ disagree, $3=$ no opinion, $4 \& 5=$ agree). Different letters stand for significant differences according to Dunn Bonferroni Test for multiple comparisons of Kruskal-Wallis evaluations. 
Table 1. Evaluations of stakeholder-data for the degree of graduates (P084: doctorate degree \& P080: vocational school degree $)($ EDUC $=$ educators, $\mathrm{PUBL}=$ public service, $\mathrm{CERT}=$ certifiers, $\mathrm{CONS}=$ consultants, $\mathrm{IMEX}=$ Import/Export, $\mathrm{SALE}=$ salesmen, $\mathrm{FARM}=$ farmers, $\mathrm{PROC}=$ processors $)$

\begin{tabular}{lllll}
\hline Code & Stakeholder & Agreement & z value & DB \\
\hline P084 & EDUC & 0.71 & 6.36 & $\mathrm{c}$ \\
& PUBL & 0.63 & 3.16 & $\mathrm{bc}$ \\
& CERT & 0.36 & 1.51 & $\mathrm{abc}$ \\
& CONS & 0.35 & 1.31 & $\mathrm{abc}$ \\
& IMEX & 0.27 & -0.54 & $\mathrm{ab}$ \\
& SALE & 0.10 & -1.94 & $\mathrm{a}$ \\
& FARM & 0.11 & -2.98 & $\mathrm{a}$ \\
& PROC & 0.12 & -3.15 & $\mathrm{a}$ \\
& FARM & 0.76 & 2.35 & $\mathrm{c}$ \\
& PROC & 0.75 & 1.50 & $\mathrm{c}$ \\
& SALE & 0.75 & 0.89 & $\mathrm{c}$ \\
& IMEX & 0.72 & 0.45 & $\mathrm{bc}$ \\
& CONS & 0.53 & -1.60 & $\mathrm{abc}$ \\
& PUBL & 0.46 & -1.83 & $\mathrm{abc}$ \\
& CERT & 0.20 & -2.64 & $\mathrm{ab}$ \\
& EDUC & 0.29 & -4.74 & $\mathrm{a}$ \\
\hline
\end{tabular}


Table 2. Evaluations of stakeholder-data for the profile of theoretical knowledge of graduates (P085: plant production \& P090: food technology) $(\mathrm{EDUC}=$ educators, $\mathrm{PUBL}=$ public service, $\mathrm{CERT}=$ certifiers, CONS $=$ consultants, IMEX $=$ Import/Export, SALE $=$ salesmen, $\mathrm{FARM}=$ farmers, $\mathrm{PROC}=$ processors)

\begin{tabular}{llllll}
\hline Code & Stakeholder & Disagree & Agree & z value & DB-test \\
\hline P085 & FARM & 0.06 & 0.82 & 2.53 & $\mathrm{~b}$ \\
& CERT & 0.05 & 0.90 & 2.20 & $\mathrm{~b}$ \\
& EDUC & 0.02 & 0.84 & 1.76 & $\mathrm{~b}$ \\
& PUBL & 0.05 & 0.89 & 1.07 & $\mathrm{ab}$ \\
& CONS & 0.07 & 0.82 & 0.86 & $\mathrm{ab}$ \\
& IMEX & 0.35 & 0.53 & -1.21 & $\mathrm{ab}$ \\
& PROC & 0.29 & 0.57 & -2.89 & $\mathrm{a}$ \\
& SALE & 0.29 & 0.50 & -3.41 & $\mathrm{a}$ \\
& PROC & 0.10 & 0.82 & 4.17 & $\mathrm{c}$ \\
& IMEX & 0.15 & 0.75 & 1.57 & $\mathrm{bc}$ \\
& SALE & 0.15 & 0.73 & 1.27 & $\mathrm{bc}$ \\
& CERT & 0.10 & 0.80 & -0.04 & $\mathrm{abc}$ \\
& EDUC & 0.15 & 0.59 & -1.08 & $\mathrm{ab}$ \\
& PUBL & 0.37 & 0.53 & -1.37 & $\mathrm{ab}$ \\
& CONS & 0.29 & 0.52 & -2.41 & $\mathrm{a}$ \\
& FARM & 0.26 & 0.54 & -3.32 & $\mathrm{a}$ \\
\hline
\end{tabular}


Table 3. Evaluations of stakeholder-data for the profile of theoretical knowledge of graduates (P085: plant production \& P089: food quality) $(\mathrm{IT}=$ Italy, ES = Spain, FI = Finland, CZ = Czech Republic, EE Estonia, $\mathrm{DE}=$ Germany, $\mathrm{PL}=$ Poland $)$

\begin{tabular}{llllll}
\hline Code & Country & Disagree & Agree & z value & DB-test \\
\hline P085 & EE & 0.10 & 0.81 & 2.52 & $\mathrm{~b}$ \\
& ES & 0.05 & 0.86 & 1.82 & $\mathrm{~b}$ \\
& FI & 0.00 & 0.94 & 0.56 & $\mathrm{ab}$ \\
& CZ & 0.10 & 0.82 & 0.11 & $\mathrm{ab}$ \\
& IT & 0.11 & 0.74 & -0.54 & $\mathrm{ab}$ \\
& DE & 0.13 & 0.65 & -2.03 & $\mathrm{a}$ \\
& PL & 0.29 & 0.58 & -2.61 & $\mathrm{a}$ \\
& ES & 0.02 & 0.87 & 4.02 & $\mathrm{~b}$ \\
& EE & 0.08 & 0.77 & 0.78 & $\mathrm{ab}$ \\
& CZ & 0.11 & 0.73 & 0.32 & $\mathrm{ab}$ \\
& FI & 0.22 & 0.67 & -0.98 & $\mathrm{a}$ \\
& IT & 0.15 & 0.65 & -1.17 & $\mathrm{a}$ \\
& PL & 0.16 & 0.58 & -1.65 & $\mathrm{a}$ \\
& DE & 0.14 & 0.67 & -2.45 & $\mathrm{a}$ \\
\hline
\end{tabular}


Table 4. Evaluations of stakeholder-data for the combined answers of requirements for the job, (1) common ranking of the individual stakeholders, (2) common ranking of the individual replies of stakeholders (EDUC $=$ educators, $\mathrm{PUBL}=$ public service, CERT $=$ certifiers, CONS $=$ consultants, $\mathrm{IMEX}=\mathrm{Import} /$ Export, $\mathrm{SALE}=$ salesmen, $\mathrm{FARM}=$ farmers, $\mathrm{PROC}=$ processors $)$

\begin{tabular}{llllll}
\hline Code & Stakeholder & Disagree & Agree & z value & DB-test \\
\hline P107 - & CONS & 0.12 & 0.75 & 7.35 & d \\
P121 & CERT & 0.12 & 0.71 & 4.24 & cd \\
& PUBL & 0.15 & 0.71 & 3.96 & cd \\
& EDUC & 0.10 & 0.70 & 6.79 & cd \\
& IMEX & 0.13 & 0.66 & 2.74 & $\mathrm{c}$ \\
& SALE & 0.19 & 0.60 & -0.59 & $\mathrm{~b}$ \\
& FARM & 0.22 & 0.54 & -6.57 & $\mathrm{a}$ \\
P115 & PROC & 0.23 & 0.54 & -6.34 & $\mathrm{a}$ \\
P108 & All & 0.09 & 0.78 & 10.38 & $\mathrm{~g}$ \\
P116 & All & 0.06 & 0.78 & 10.03 & fg \\
P114 & All & 0.10 & 0.76 & 7.00 & efg \\
P118 & All & 0.11 & 0.71 & 4.88 & $\mathrm{defg}$ \\
P120 & All & 0.10 & 0.68 & 3.95 & $\mathrm{defg}$ \\
P107 & All & 0.07 & 0.70 & 3.35 & $\mathrm{defg}$ \\
P119 & All & 0.12 & 0.63 & 2.46 & $\mathrm{def}$ \\
P112 & All & 0.17 & 0.58 & 1.25 & $\mathrm{de}$ \\
P110 & All & 0.21 & 0.56 & -0.76 & $\mathrm{de}$ \\
P117 & All & 0.26 & 0.54 & -2.64 & $\mathrm{~d}$ \\
P111 & All & 0.22 & 0.51 & -2.94 & $\mathrm{~cd}$ \\
P121 & All & 0.33 & 0.35 & -10.24 & $\mathrm{bc}$ \\
P113 & All & 0.42 & 0.33 & -11.46 & $\mathrm{ab}$ \\
P109 & All & 0.63 & 0.25 & -17.85 & $\mathrm{a}$ \\
\hline
\end{tabular}

